\title{
PHOTOVOLTAIC POWER GENERATION FOR SUSTAINABLE DEVELOPMENT
}

\author{
${ }^{1}$ Evbogbai M. J. E. \\ evbogbaiedekin@edouniversity.edu.ng \\ ${ }^{2}$ Ogbikaya S. \\ ogbikaya.stephen@edouniversity.edu.ng \\ ${ }^{1 \& 2}$ Department of Electrical and Electronic Engineering, Edo University Iyamho, Nigeria. \\ All correspondence should be directed to Engr. Prof. Evbogbai M. J. E. evbogbaiedekin@edouniversity.edu.ng \\ DOI: $10.31364 / \mathrm{SCIRJ} / \mathrm{v} 7 . \mathrm{i} 4.2019 . \mathrm{P} 0419630$ \\ http://dx.doi.org/10.31364/SCIRJ/v7.i4.2019.P0419630
}

\begin{abstract}
The effect of environmental conditions on photovoltaic modules is presented in this work. The average terminals voltages of three solar panels of 6,12 and 33volts mounted on a gabbled rooftop of about 15meters high were examined for different priods.The result from the experiment reveals that the 6,12 and 33volts panels by 7.30am generate their respective rated voltages. Further examination shows that between 12.00 noon and $1.00 \mathrm{pm}$ local time, the panels output were maximally $9,20.2$ and 38 volts respectively. Beyond $6.30 \mathrm{pm}$ the voltage readings from the panels decreases virtually to zero. Plots of the average voltage generated for different periods revealed time and cloud dependence. The voltages generated also depend on its angle of inclination with respect to the sun and location of the site. The result from the experimental data depict that photovoltaic power generated is sustainable and can satisfactorily power both domestic and industrial loads for capacity building.
\end{abstract}

Keywords: Photovoltaic Effect, Environmentally Friendly, Site, Electrical Power System

\section{INTRODUCTION}

The socio-economic and political development and technological advancement of any nation to a large extent depends on its energy sector. Despite the abundant energy resources available in world, we are still confronted with the problem of energy crisis. This crisis stem from over dependence and worldwide shortage of hydrocarbon based fuel resulting from prolong crisis in the Gulf region and the endless crisis in the Niger delta region of Nigeria. These two regions in the world are the major producer and exporter of crude oil in the world market. The state of insecurity in the United State of America, another major producer and consumer of crude oil and the fear that the hydrocarbon based energy resource is exhaustible further compound the crisis.

The advantages associated with petroleum products resulting from fractional distillation of crude oil led to the neglect and exploration of other viable energy resources. The over dependence on this commodity and its socio-economic implications and control gave rises to the strife in these regions. It therefore follows that the crisis have political undertone on resources control. These crises in the case of Nigeria, activities of the militants such as hostage taking and kidnappings of oil workers remain the bane in the 
extraction and exploration new oil wells. In addition to these crises, the hydrocarbon based energy resources are exhaustible and unenvironmentally friendly.

The climate change (Awake, Jan.22,1993; Dec.22,1994 and Jan.8,1996) resulting from the depletion of the ozone layer due to carbon mono oxide and other poisonous emissions from hydro carbon based fuel has politically, polarized the developing nations against the developed ones, hence in the submit on climate change, the argument is, the developed countries are the major consumer of hydrocarbon based fuel, hence they are the major contributors of the hazardous emission into the atmosphere and that they should bear the cost by evolving emission reduction technique and compensate adequately, the developing countries. Considering the political maneuvering and cost implication, the advanced countries are opting for zero emission technology (Fairley, 2007; Voelcker, 2007).

The discovery of electricity and consequent invention of electrical machines revolutionised the energy sector and the drive industries. The transformation of other energy resources to electrical energy became pertinent because of its inherent advantages. The prominent method of electrical power generation had been hydro, thermal and nuclear. Out of these three energy resources only hydro is renewable and better environmental impact control mechanisms. Other renewable energy resources such as solar, wind, geothermal, biomass, tide and wave have not been fully harnessed (Gupta, 2007).

Solar energy produces effects such as lighting, heating and drying. In spite of the fact that photovoltaic effect was discovered by Edmod Bechuer in 1839 and subsequent production of practical solar cells by Bell Laboratory in 1954(Evbogbai and Nsiah, 2008), the direct conversion of solar energy to electrical energy using photovoltaic modules has not been given adequate attention. Only few advanced countries such as U.S.A., Japan, and UK had incorporated it into their power grid (Litifu , Nemoto, Ushiyama and Nagasaka , 2007).

Considering the disposition of Nigeria based on its geographical (tropical zone) location latitudes $4^{\circ}$ and $14^{\circ}$ North of the equator (Animalu, 1983). She had been classified amongst the countries in the world with immerse solar energy potentials which can be converted to electrical energy for the betterment of all and sundry. The solar radiation level on a horizontal surface in Nigeria ranges between $3.7 \mathrm{kWhm}^{-2}$ day $^{-1}$ along the vast areas to about $7.0 \mathrm{kWhm}^{-2}$ day $^{-1}$ along the semi arid zone. A greater percentage of Nigeria receives on the average a solar radiation level of about $5.5 \mathrm{kWhm}^{-2}$ day $^{-1}$. The solar radiation is attenuated during harmattan and raining season. The country receives about $5.081 \times 10^{2} \mathrm{kWh}$ of energy per day from the sun with more than $2000 \mathrm{hours}$ sunshine per year. The use of solar appliance with 10 percent efficiency to cover 1 percent of the country's surface could generate output equivalent to about 10million barrels of oil per day. This is about eight times the present level of oil production in Nigeria (Ekeh,2003).

After almost four decades of the existence of the electricity industry in Nigeria and 50 years of independence, the electricity industry in Nigeria is still finding it difficult to start. Billions of US dollars had been invested in this sector between 1999 to date, the WWW.scirj.org 
theoretical $6,000 \mathrm{MW}$ is in doubt as evident by the epileptic supply. Inspite of the huge, untapped solar energy potential available for electrical power generation in Nigeria, the present Federal Government of Nigeria is opting for nuclear power stations as a way of meeting energy demand. It is true that high amount of electrical energy can be obtained from the nuclear reactions involving uranium or plutonium. The question of the chain reaction control and toxic waste disposal are fundamental for the regulatory agencies to address before embarking on such high tech venture.

The effects of time of the day, weather, season and site location on the quantity and quality of voltage generated has been reported (Evbogbai and Nsiah, 2008; Evbogbai, Ogieva and Oshenvemwa, 2009). However these effects on three photovoltaic modules from different manufacturers were to be examined. An experimental demonstration of the conversion of solar energy to power ac loads are also presented. This work is to address the electric energy in balance in Nigeria by effectively utilizing the solar energy potential for the generation of electricity. The scheme would be suitable for rural electrification, isolated communities and grid-tied.

The angular position of the sun at solar noon, with respect to the plane of the equator (declination) is given by Cooper's equation (Minister of Natural Resources, 2004):

$$
\delta=23.45 \sin \left(2 \pi \frac{284+n}{365}\right)
$$

Where $\mathrm{n}$ is the day of the year (i.e. $\mathrm{n}=1$ for January $1, \mathrm{n}=32$ for February 1 ). Declination varies between $-23.45^{\circ}$ on December 21 and $23.45^{\circ}$ on June 21.

The solar hour angle is equal to zero at solar noon and varies $15^{\circ}$ per hour from solar noon.

The sunset hour angle $\omega_{s}$ is given by

$$
\cos \omega_{s}=-\tan \psi \tan \delta
$$

Where $\psi$, is the latitude of the site and $\delta$ is the declination

The monthly average clearness index, $\overline{K_{T}}$ is given by the equation

$$
\overline{K_{T}}=\frac{\bar{H}}{\overline{H_{o}}}
$$

Where $\bar{H}$ is the monthly average daily solar radiation on a horizontal surface and $\overline{H_{o}}$ is the monthly average extraterrestrial daily solar radiation on horizontal surface. The value of $\overline{K_{T}}$ depend on the location and the time of the year. It is 0.3 for overcast climate and 0.8 for very sunny locations.

The array energy $E_{A}$ available to the load and battery (Chihchinag and Chihming, 1998) is 


$$
E_{A}=E_{P}\left(1-\lambda_{P}\right)\left(1-\lambda_{C}\right)
$$

Where $E_{P}$ energy delivered by the PV array, $\lambda_{P}$ is miscellaneous $\mathrm{PV}$ array losses and $\lambda_{C}$ are other power conditioning losses.

The overall array efficiency $\eta_{A}$ (Ying-Tung and China-Hong, 2002), is

$$
\eta_{A}=\frac{E_{A}}{S \overline{H_{t}}}
$$

Where $\mathrm{S}$ is the actual tilt angle in degree and $H_{t}$ is the hourly irradiance in the plane of the PV.

\section{MATERIALS AND METHODS}

\section{MATERIALS}

The materials used in these experiments includes

140watt, 33volts Dc, shell Bp type, photovoltaic module

Two 100Watts, 12Volts, MBF: 100 Type, photovoltaic module,

10watt, 6volts Dc, shell Bp type, photovoltaic module

10 Ampere Auto switch solar charge controller (Regulator)

266clamp on Ammeter, Oscilloscope,

4mm copper conductors and two $12 \mathrm{Volt}, 120 \mathrm{AH}$ storage batteries.

Digital Voltmeter (DT9205A), Digital Ammeter (DT9205A),

Variable resistive Loads 200-1600Watts and Crocodile Clips.

\section{EXPERIMENTAL PROCEDURE}

\section{Experiment 1}

Two copper conductors of diameter $4.00 \mathrm{~mm}$ and $20 \mathrm{~m}$ in length were connected to the terminals of each of the solar panels mounted on the rooftop of electrical engineering workshop $15 \mathrm{~m}$ high for direct exposure to sunlight. The other ends of the copper cond uctors are connected to digital voltmeter to measure the terminal voltage of the panels. The experiment was conducted over a period of one year, from $6.00 \mathrm{am}$ to $6.00 \mathrm{pm}$ (local time). From the data obtained, the annual average voltage-time curves for different panels were plotted.

\section{Experiment 2}

Figure 1 shows the connection diagram of solar power system. It was used to demonstrate the conversion of solar energy into electrical energy. It consist of two 100watts, 12volts panels connected in series to boast the panels output voltage, which feds a 24 volts, 5ampere solar charge controller. The output of the charge regulator feeds the inverter via two 100AH, 12volts series 
connected batteries. After the batteries had been fully charged the solar charger was disconnected. The energy stored in the batteries was used to power eight 200watts filaments (resistive loads). The experiment was conducted in steps by bulb addition. The current drawn by the load and the terminal voltage of the batteries were recorded and the characteristics curves for these experimental data were plotted.

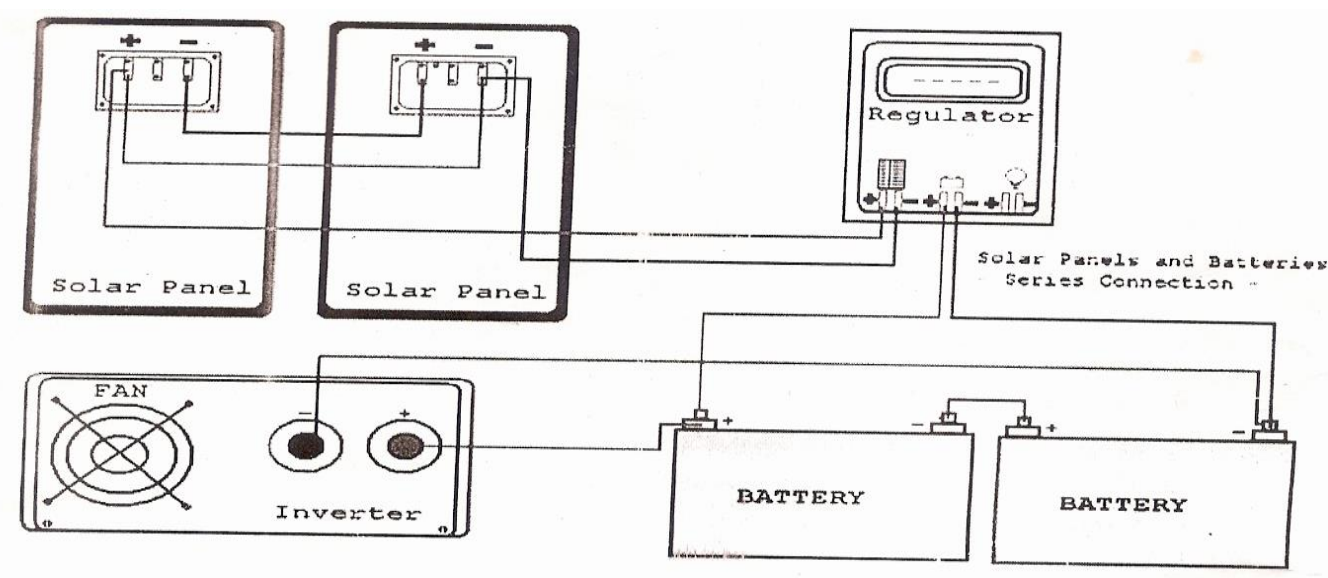

Figure 1 Connection diagram of solar power system

\section{RESULT AND DISCUSION}

The voltage-time characteristics of 6,12 and 33volts solar panels from different manufacturers are shown in Figure 2. A critical examination of the curves shows analogous behaviour, depicting voltage characteristics which depend on their specification. The two extremes of the curves $6.00 \mathrm{am}$ and $7.00 \mathrm{pm}$ show virtually zero voltage. This indicates that at night time, due to the rotation of the earth, the intensity of the sun is very low, hence the functional voltage generated were very insignificant. It therefore means that excess energy should be generated during the day and stored in the batteries fore latter usage at night.

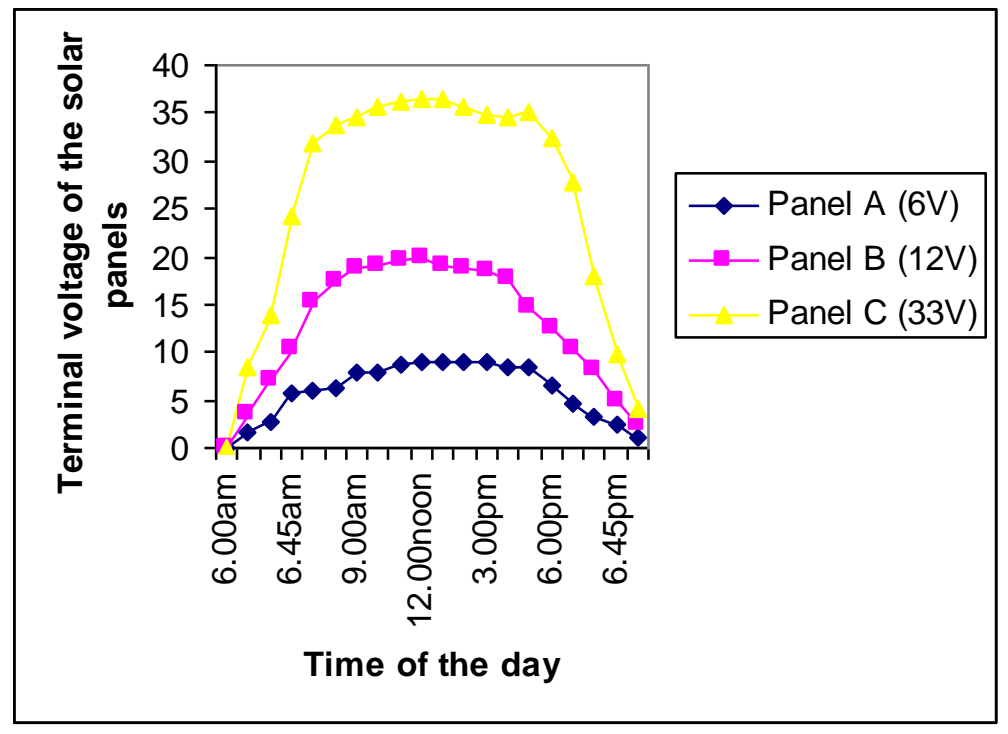

Figure 2 Time dependence of the terminal voltages of three solar panels from different manufacturers. 
As the time progresses, by 7.30am, the panel generates their respective rated voltages of 6,12 and 33 volts. By solar noon which corresponds to $1.00 \mathrm{pm}$ local time in Nigeria, the intensity of the sun is at its maximum, hence the maximum voltages of $9,20.2$ and 38volts were recorded by these panels respectively. By 8.00am the panel generates voltages higher than their rated voltages. This resulted from the fact that the solar constant in Nigeria is $1361.0988 \mathrm{~W} / \mathrm{m}^{2}$ (Babatunde, 1985) as against $1000 \mathrm{~W} / \mathrm{m}^{2}$, rated value for the panels. From the result, it is obvious that Nigeria has solar energy potential, which if properly harnessed can meet her electrical energy need for sustainable national development.

Figure 3 shows the voltage-time characteristics and the regulated output voltage of the charge controller of Figure 1. From the Figure it is clear that between 7.00am and 6.00pm, the batteries were been charged and the energy can be used simultaneously to power dc loads of appropriate ratings or power ac loads via inverter. Any excess energy will be stored for latter usage at night.

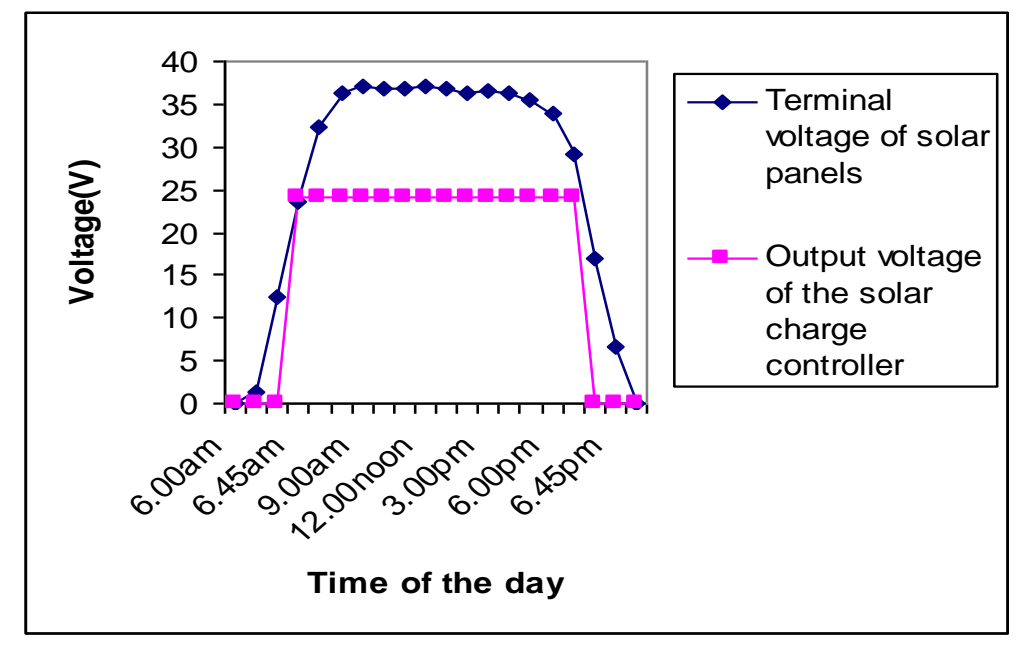

Figure 3 Voltage-Time characteristics of a solar power system of Figure 1.

Figure 4 shows the load-current characteristics of $1.4 \mathrm{kVA}, 220 \mathrm{~V}, 50 \mathrm{~Hz}$, single inverter, while Figure 5 shows the effect of load variation on the terminal voltage of the batteries. Figure 4 clearly shows that a linear relationship exist the load and current drawn. Figure 5 depict the characteristics exhibited by a fully charge battery under varying load condition without energy replenishment to the batteries, especially at night when the terminal voltage of the panels are virtually zero. The curve shows that an inverse step relationship exist, between the load and the terminal voltage of the batteries. Figures 4 and 5 indicate that the AmpereHour ratings of the batteries, the loads and time of usage are significant factors which cannot be ignored when selecting batteries for solar power system. The ratings and number of solar panels to met electrical energy need is load dependence. The design procedure for that has been reported elsewhere. 


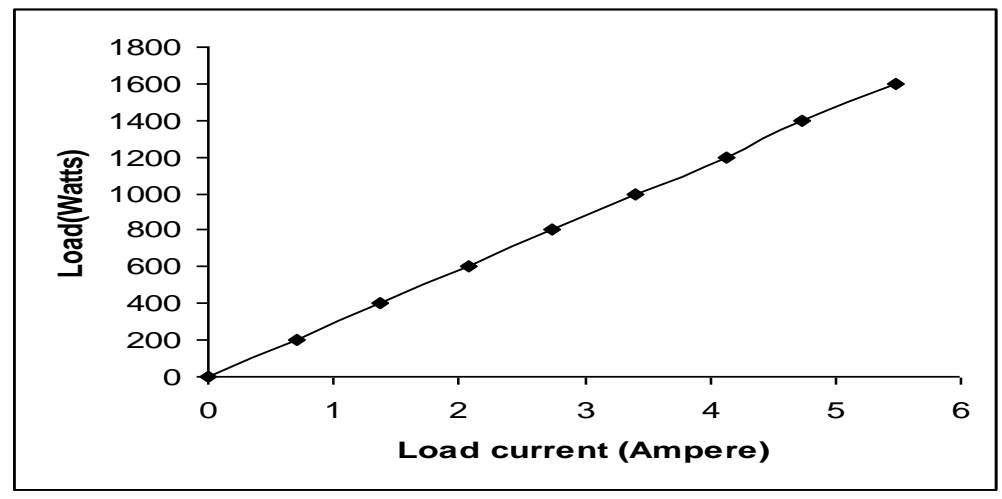

Figure 4 Load-current characteristics of $1.4 \mathrm{~kW}, 220 \mathrm{~V}, 50 \mathrm{~Hz}$ inverter.

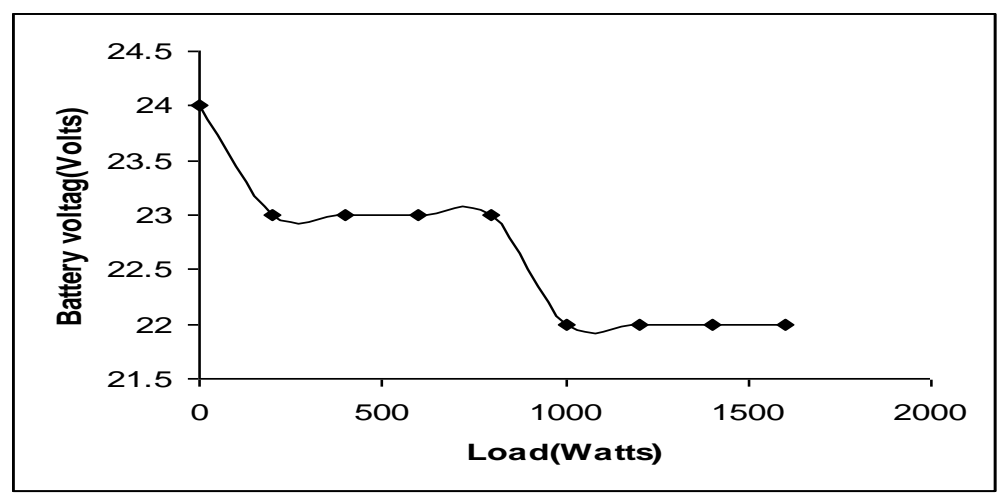

Figure 5 Effect of load on the terminal voltage of the battery.

\section{CONCLUSION}

It must be emphasized that, it is not every community that have water resources for hydro, thermal or nuclear power generation, but the solar energy is available for every body, hence if harnessed can sustain the electrical energy need for meaningful development in Nigeria. Although the initial cost implication may be high, but on the long run, it is more economical because of its renewable nature, less maintenance cost and its environmental friendliness.

For sustainable development to take place in Nigeria, the government, corporate bodies and individuals should focus on photovoltaic power generation as one of the most viable option that could drive the civilization for ever.

\section{REFERENCE}

Animalu, A.O.E,(1983), "Solar Energy Training Research and Development in Nigeria”, Nigerian Academy of Science, Vol. 5, , pp.8.

Awake;(Jan.22,1993), “Our Battered Earth who will rescue it?”, Watchtower Bible and Tract Society of New York, Inc., pp. $3-8$.

Awake;(Dec.22,1994), “Can Our Atmosphere be Saved?”, Watchtower Bible and Tract Society of New York, Inc., pp. 3-9. 
Awake;(Jan.8,1996), “Our Threatened Planet, Can it be saved?”, Watchtower Bible and Tract Society of New York, Inc., pp. 3-11.

Babatunde, E.B.,(1985), "Soft Decentralized Solar Option for Nigeria", Proceedings of workshop on the physics and Technology of Solar Energy Conversion, University of Ibadan, 4-7 August, 1985.

Chihchinag H. and Chihming S.,(1998), "Study of Maximum Power Tracking Techniques and Control of DC/DC Converters for Photovoltaic Power system"IEEE.

Ekeh J. C.,(2003), “Electric Power Principles” First Edition, Amfitop Books Lagos.

Evbogbai M.J.E. and Nsiah I.K.,(2008), “ The Impact of Time on Photovoltaic Power Generation in Nigeria”,Global Journal of Engineering And Technology, Vol.1, No.4, Pp465 - 471.

Evbogbai M.J.E; Ogieva F.E. and Oshenvemwa A.O. (2009), "Voltage - Time Characteristics of Solar Panel in Ambrose Alli University, Ekpoma Nigeria”, International Journal of Electrical and Power Engineering, Vol.3, No.1, Pp31-35 Medwell on line Journals.

Fairley P.,(Nov.,2007), "California to Rule on Fate of Electric Vehicles-Regulators rethinks Electric-Drive Options”, IEEE Spectrum, pp 10-12.

Gupta J.B, (2007), “A course in Power System Tenth Edition, S.K. Kataria and Sons, Nai Sarak, Delhi, Pp.152.

Litifu Z., Nemoto Y., Ushiyama I., and Nagasaka K., (2007), "Realization and Analysis of a Triple Hybrid Power System Consisting of Biomass, Wind and Solar Generators" International Journal of Electrical and Power Engineering International Journal of Electrical and Power Engineering, Vol.1, No.4, Pp. 384-385.

Minister of Natural Resources, (2004), “Clean energy project Analysis”, RETSreen International, Canada, Pp. Pv 17.

Voelcker J.,(Sept.,2007), “Lithium Batteries take to the road”, IEEE Spectrum, pp 18-23.

Ying-Tung H. and China-Hong C.,(2002), "Maximum Power tracking for Photovoltaic Power System”, IEEE. 